\title{
Method for determining the starting moment of hydrate formation on the basis of optical effects
}

\author{
Nazar Pedchenko ${ }^{1}$, Yuriy Vynnykov ${ }^{1}$, Larysa Pedchenko ${ }^{1}$, and Mykhailo Pedchenko ${ }^{{ }^{*}}$ \\ ${ }^{1}$ National University "Yuri Kondratyuk Poltava Polytechnic", Oil and Gas Engineering and \\ Technology Department, 24 Pershotravnevyi Ave., 36011, Poltava, Ukraine
}

\begin{abstract}
The problem is analyzed of hydrate formation in the systems of gathering and treating of oil and gas products. The methods are studied for prevention of complications associated with the gas hydrates accumulation in the pipelines and process lines. Attention is focused on the significant material costs to prevent the hydrate formation and ways to reduce them. The necessity of constant laboratory monitoring for reservoir systems at industrial facilities to determine the hydrate formation parameters has been substantiated. The need to improve the method for determining the hydrate formation parameters for complex reservoir systems based on a mixture of hydrate-forming gases has also been proved. The purpose of the work is to improve the research method of reservoir systems immediately at the facilities of products mining and treatment. The peculiarities are analyzed of the method of visual laboratory observation in the study of gas hydrates. During experimental studies, optical effects of image distortion are observed due to the formation of a gas hydrate layer in the form of a film on the interphase surface. The mechanism of their formation, as well as the processes determining them have been substantiated. Based on this effect, a method of fixing the hydrate formation initial stage (beginning of crystal growth - mass crystallization) is proposed. For increasing the informative ability of the obtained images of hydrate formation processes, it is proposed to "paint" them with the help of colored light sources, as well as to regulate the intensity and direction of illumination. A number of photos are presented, which clearly illustrate the processes described in the paper.
\end{abstract}

\section{Introduction}

The unique ability of gases and water under certain thermobaric conditions to form gas hydrates, on the one hand, led to the formation of colossal methane deposits in its composition [1-3], and, on the other hand, created a significant problem for the oil and gas industry. Analysis of the technological operations assignment, as well as corresponding equipment of the technological chain of recovery, treatment and transportation of natural gas and oil (associated gas) evidences that a significant part of them (directly or indirectly) relates to the preventing hydrate formation [4-6]. Therefore, the cost of preventing hydrate formation is a significant part of the hydrocarbon production cost.

*Corresponding author: pedchenkomm@ukr.net 
Gas hydrates are formed at high pressures and low temperatures [7, 8]. Gas hydrates can be formed inside pipeline under certain pressure and temperature conditions, slowing or completely stopping the flow of oil and gas. It is generally difficult to remove hydrate plugs, and this can cause considerable damage to production facilities, such as line rupture and create a serious safety and environmental hazard.

A complex of techniques to prevent hydrate formation is used in the process of developing hydrocarbon deposits. At the same time, in most cases it is impossible to achieve their hydrate-free operation mode only observing the appropriate thermobaric conditions. In this case, it becomes necessary to use substances - inhibitors of this process. Although methanol is currently the most widely used inhibitor of hydrate formation in Ukraine, a number of its "competitors" are known. Each of the process inhibitors, due to its specificity and the specificity of the application object requires a careful assessment of the effectiveness and application rate. An enormous expense for hydrate prevention and mitigation is associated with the use of traditional thermodynamic hydrate inhibitors (THIs), such as methanol and mono-ethylene glycol (MEG) [9]. Thermodynamic hydrate inhibitors (methanol, ethylene glycol) are generally used in Ukraine to avoid gas hydrate problems in the line of natural gas production and transportation.

However, despite the achievements in the study of the gas hydrates properties, significant practical experience in their prevention, scientific innovations and technical improvements, the problems of combating such complications remains relevant [10]. In such a context, safe and economical hydrate management strategies have become an urgent need for safe and reliable production of oil and gas [11]. An additional option may be to develop the techniques for detecting early signs of hydrate formation in order to give operators sufficient time to take proper action for preventing blockage formation.

The past years has witnessed new technologies for providing the required information for the field operators to understand how close the gas hydrate system is thermodynamically to hydrate formation conditions, termed as gas hydrate early warning and monitoring systems. In order to optimize gas hydrate inhibitor injection, numerous different analytical techniques are used. Various advanced analytical techniques also have been used to identify gas hydrate structures and respective interactions at the boundary of aqueous - vapor interphase.

Besides, the study of gas hydrate formation and dissociation has great importance in the oil and gas industry to define operational conditions that ensure the flow of oil and gas through pipelines [12]. For example, the Centre for Gas Hydrate Research at Heriot-Watt University has proposed new techniques for detecting early signs of hydrate formation in order to give operators sufficient time to take appropriate measures [13]. In the work [14], one of these early warning techniques is presented. This technique is based on a change in the composition of the gas phase caused by hydrate formation.

It is well known that due to the formation of hydrates and the corresponding selective capture of natural gas components in hydration cells, the composition of the gas phase changes [15]. Based on the measurement of the sound velocity and thermal conductivity, the device measures equivalent concentration of gas mixture components [14]. Based on this property, an experimental technique has been developed to identify early signs of hydrate crystals formation by determining the gas composition [16].

Yang et al. [17] have developed a reliable and fast technique for measuring the concentration of salts, thermodynamic and kinetic hydrate inhibitors in the aqueous phase based on integrated data collection on electrical conductivity and acoustic velocity of aqueous phase chemical composition that leads to the determination of hydrocarbon fluid composition and, accordingly, hydrate stability zone recognition.

Tohidi et al. [16] also proposed a method for determining the stability margin of hydrate zone based on water content measurement in the gas phase. 
Additionally, Tohidi et al. [18] have proposed some techniques, such as as hydrates monitoring and warning systems, which are based on freezing point and dielectric properties measurements. They used the freezing point decrease of the aqueous phase to estimate the hydrate recovery temperature of reservoir fluids in the presence of salts and inhibitors using a simple equation.

At the same time, the complex of gas hydrates properties, the diverse composition of reservoir systems, a wide range of thermobaric parameters and their variability will not allow to obtain an acceptable result when applying most of the known methods. Therefore, the improvement of the technique for operational predicting of hydrate formation in the systems of gathering and treatment of industrial products, as well as the schematic diagram of the equipment for its implementation is relevant.

\section{Situation analysis and purpose setting}

For the natural gas hydrates formation, in addition to the appropriate temperature and pressure, the presence of moisture in the condensed phase is necessary. In the wellbore, this requirement is always met, since the gas is always saturated with water vapor in reservoir conditions. When moving along the wellbore and further along the gathering and treatment system, the gas temperature decreases, resulting in moisture condensation.

As known, the system composition influences on the equilibrium conditions. Hydrate crystalline structures are composed of water molecules linked by hydrogen bonds that form a lattice. The size of the guest molecule determines the type of structure to be formed. The composition of the gas mixture can influence on the thermodynamic hydrate equilibrium. It is known that the hydrates formation is characterized by two distinct stages, such as nucleation and growth [19]. After this, the gas hydrates agglomeration begins (the stage of phase transition, after which the hydrate plugs formation occurs) [20]. Also, the composition of the gas phase affects the gas hydrates morphology and crystal growth [21].

Besides, the rate of nucleation strongly depends on the thermal history of the system [22]. According to Bishnoi et al. [23], the induction time for nuclei formation depends on the aqueous phase history. This property and the results of it manifestation are called the memory of water. Hydrate memory can be described as the effect in which hydrates can be more easily formed from a mixture of gas and water, resulting from the hydrates dissociation, compared to the case where hydrate is formed for the first time from a mixture of water and gas without any previous hydrate history. This effect suggests that hydrate formation can be promoted by multiple dissociation and reformation processes [24].

The studies relate this memory to a residual structure (consisting of particles of hydrate cells or polyhedral clusters) [21] or persistent hydrate crystallites [25]. They concluded that this local change in water structure due to the presence of hydrate crystallites could be responsible for memory effect. In other words, persistent hydrate crystallites in dissociated hydrate water lead to a locally modified water structure, which, in turn, facilitates hydrate transformation [25]. Sloan et al. [26] reported residual structures after hydrate dissociation by measuring the apparent viscosity (using a sapphire rolling-ball viscometer) during hydrate formation and dissociation. Based on this observation, they recommended immediate removing of dissociated hydrate water from pipeline for preventing rapid repeated formation of hydrates.

Thus, in addition to pressure and temperature, the history of water, the degree of supersaturation or supercooling [27], the stirring rate [28], and the ratio of molecular diameter to cavity size [29] are variables that affect the induction time.

Thermodynamic models (for example, described in the work [30]) are usually used to calculate the hydrate safety margin based on the worst conditions. Based on the calculations, the inhibitors are injected. However, as shown above, there is a difficulty in 
qualitative assessment of all reservoir system components and the results of their interaction. In work [31], the simulation results demonstrated that the data on hydrate composition obtained from direct measurement (microscopic tools) are well assessed by the thermodynamic model. However, when structural transition can occur in a system, the thermodynamic model is no longer accurate. Consequently, in order to create a guaranteed and certainly sufficient anti-hydrate strength margin of the system, the application rate of the inhibitor is significantly increased. As a result, this approach leads to a systematic overuse of the reagent (and hence financial costs), but, as practice shows, does not eliminate the threat of hydrate plugs formation. In addition, such a large strength margin can have a significant impact on the environment.

This problem is solved by obtaining reliable (and most accurate) data as a result of corresponding measurements and laboratory tests directly at the production site. Today, modern equipment is used for laboratory study of gas hydrate properties. A significant number of effective techniques have been developed. The most commonly used apparatus include autoclave, a vibrating cell, stirred reactor, batch or semi-batch crystallizer, automated lag time unit (HPALTA), (micro) differential scanning calorimetry (DSC or $\mu$-DSC), pipe wheel, and flow loop. The selection of a proper experimental setup largely depends on the purpose and perspective of research. Different flow loops with a variety of dimensions and operating conditions have been widely used to study the nature of hydrate plugging, depositing mechanisms and induced flow patterns under variable flow velocities and water cuts [32, 33] for water dissolved in a liquid condensate system [34] and multiphase systems [35] with/out inhibitors [36] with/out emulsion systems [37].

It is evident that the research method and design features of the involved laboratory equipment depend on the purpose of its implementation, the required level of the studied parameter accuracy and the available budget (financial capacity or economic feasibility). Any research to control production processes must be as reliable as possible, integrated into the process and conducted systematically (continuously). On the other hand, laboratory research, like any other business activity, has its cost. It consists of the cost of equipment and the cost of performing (conducting) research. In turn, the cost of laboratory equipment and research, as well as the level of their reliability, depend on the method used.

The extracted products of gas, gas condensate and oil wells are a complex multicomponent mixture of hydrocarbons and non-hydrocarbons (including water vapor, condensed water with different levels of mineralization and composition, technological fluids, dispersed solid rock fraction and drilling fluid) components of natural and technogenic origin, the composition of which and parameters vary depending on the field, the stage of development and the stage of the technological process of preparation.

As shown above, gas hydrates are non-stoichiometric compounds, the composition, morphology and level of stability of which depend not only on thermobaric parameters, but also on a number of other additional factors. These include the effect of self-preservation, the manifestation of water memory, influence of soluble and insoluble impurities of the reservoir system, as well as technological fluids, etc. on the direction and speed of the process (catalyze or inhibition). Therefore, in the technological cycle of hydrocarbon production, it is difficult and sometimes impossible to predict and assess their impact, as well as take into account and respond to them.

Against the background of reducing the energy prices at Ukrainian enterprises, it is extremely important to minimize the operating costs of hydrocarbon production. At the same time, the purchase of inhibitors for hydrate formation and the measures related to prevention of the hydrate plugs formation are significant expenditure items. Significant savings can be achieved based on the most accurate and operational data on the zones of possible hydrate formation and the application rate of inhibitors. Thus, based on the above, the urgent task is to further improve the regular and operational laboratory studies of real 
reservoir systems immediately at the facilities of products mining and treatment. In addition, the equipment and techniques used for this should be as efficient, reliable and inexpensive as possible.

\section{Method for determining the starting moment of mass gas hydrate crystallization}

The hydrate formation process is exothermic and is fixed in a closed volume by the pressure drop. Extremely sensitive (but at the same time quite complex and expensive) equipment is used to control the change of thermobaric parameters during this phase transition. The initial stage of the process is nucleation (the stage of gas dissolving in the liquid is irrelevant for reservoir systems).

Determining in the laboratory conditions of the beginning of hydrate formation by known methods (by temperature jump, pressure drop or increase in resistance), even with the use of supersensitive equipment, in our opinion, mainly concern the period of mass gas hydrate crystallization (this is especially true for studying the complex reservoir systems directly in the process their extraction). That is, the moment when the water molecules (or their part) are appropriately structured and the system has already accumulated a certain (quite significant) amount of gas hydrate nuclei. Moreover, in the case of real reservoir systems, as a result of the fractionation effect, the formed microcrystals will be beneficiated with heavier gas components. Over time, within a closed system, the difference in the composition of gas from the original one, and, hence, the error will increase. Thus, in our opinion, the methods of hydrate formation parameters control and appropriate equipment, acceptable for widespread use in industrial facilities of Ukraine, do not allow to record the stage of beginning the hydrate crystals growth around its nuclei and even the start moment of their mass crystallization. The question of how this affects the quality of the information obtained and ways to use it will be left open.

At the same time, information about the earlier stages of the process (nucleation, or at least the beginning of mass crystallization) will definitely be more important for operative response. It is known that the process of gas hydrate formation is the most intense at the interphase (gas and water) boundary. The process at the interphase boundary (liquid surface, droplets and bubbles in the laboratory reactor or process equipment) is manifested in the formation of a thin hydrate layer in the form of a film. Visually, this process is fixed by the transformation of the mirror-like surface of the interphase boundary to matte one. The dynamics of this process is illustrated in Figs. 1 and 2.

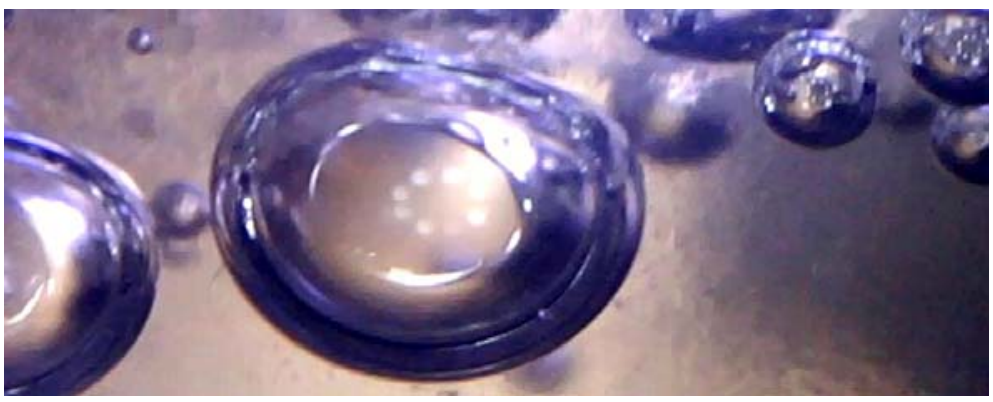

Fig. 1. Mirror-like interphase surface of hydrate-forming gas bubbles in water (gas hydrate film is absent).

This effect of the interphase boundary distortion is explained by the formation, growth, chaotic accumulation and localization at this boundary (through to the intermediate density between water and gas) of hydrate microcrystal of different shapes and sizes. 


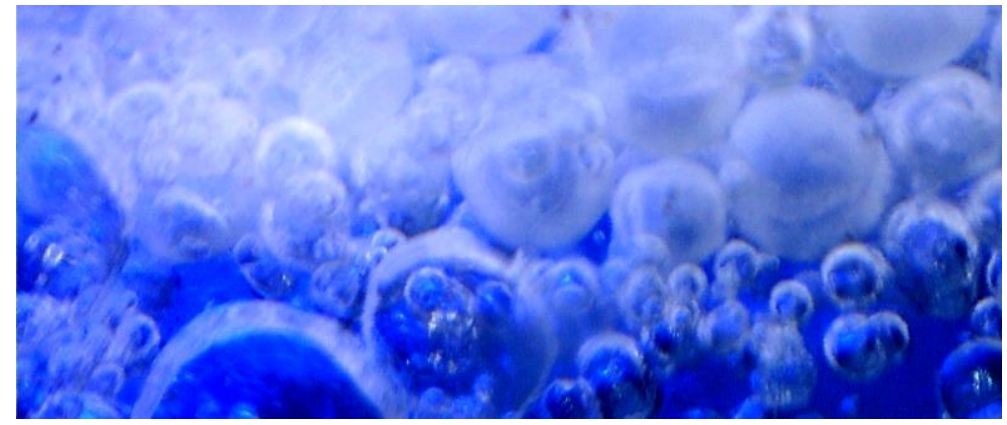

Fig. 2. Matte interphase surface of hydrate-forming gas bubbles in water (gas hydrate film is formed).

At the same time deviations of thermobaric parameters at this stage are practically not fixed. Thus, according to this method, the earlier stages of the hydrate formation process can be recorded. However, even under such conditions, it is quite difficult as clearly as possible (unambiguously) to record the moment of "turbidity" of the interphase surface.

However, in the process of processing the obtained visual information of the hydrate formation dynamics on the interphase surface, the following is found: when turning on the additional light sources placed around the perimeter of the digital microscope lens, the images of droplets and bubbles recorded on photo and video were distorted by reflection of these light sources (Fig. 3).

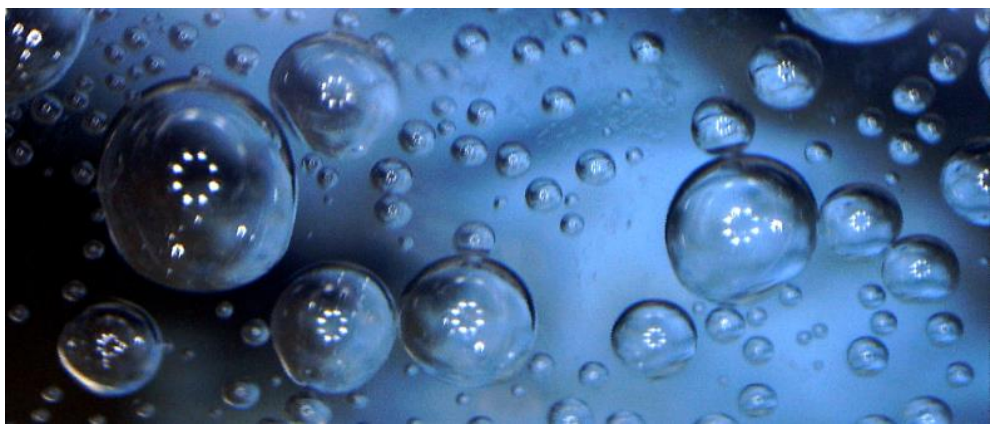

Fig. 3. Defects on the images of gas bubbles in water, formed as a result of reflection on their surface of point light sources.

However, when analyzing the whole dynamics of the phase transformation process in these images, it has been revealed that simultaneously with the interphase surface turbidity, there is a significant distortion of the spots of the light source reflection. Moreover, the beginning of its distortion was recorded much earlier than it was possible to visually notice the turbidity of the bubble or drop surface. This process is illustrated in Fig. 4.

As can be seen in the photo (Fig. $4 \mathrm{~b}$ and $4 \mathrm{c}$ ), there are practically no other visual signs of the hydrate formation process, except for the distortion of the light reflection of the diodes. Thus, this optical effect makes it possible to extremely sensitively (with high accuracy) record the changes occurring at the microlevel with a mirror-like interphase "gas - liquid" surface. In our case, it allows to record the initial stage of the crystals growth process of gas hydrate. Thus, the optical effect of image distortion is proposed to be used as basis for the method for determining the start moment of hydrate formation (the stage of beginning of the crystals nuclei growth) for complex reservoir systems in industrial production. 
(a)

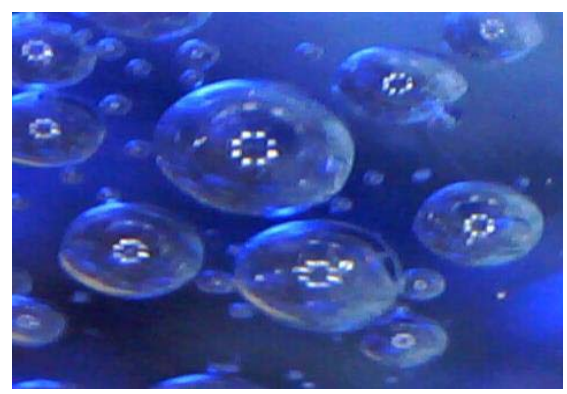

(c)

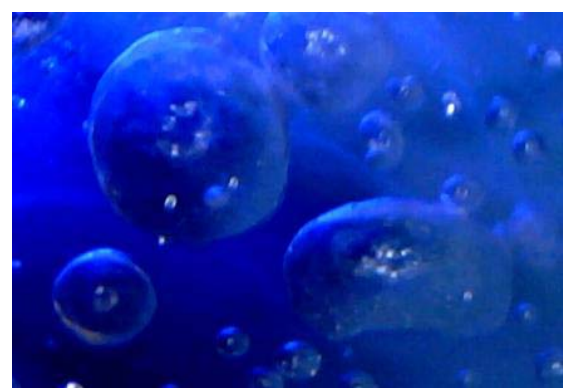

(b)

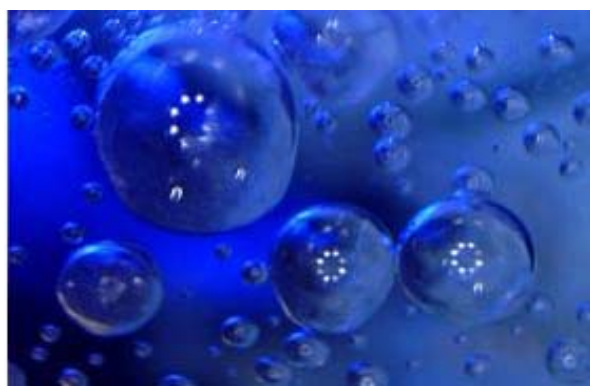

(d)

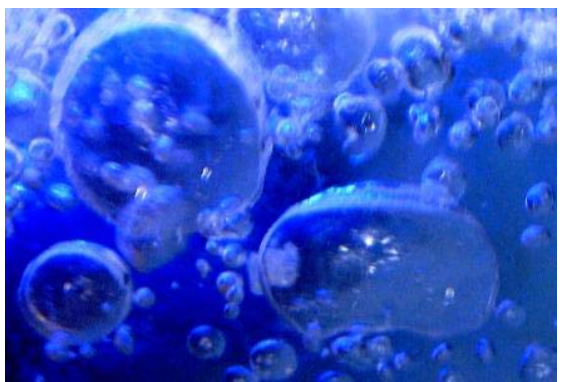

Fig. 4. Dynamics of distortion of point light sources reflections on the images of gas bubbles in water as a result of the gas hydrate film formation on the interphase surface.

\section{Laboratory research peculiarities and results}

The method of visual observations is the simplest, but at the same time extremely informative. Quite often it is used in the study of gas hydrates. In the work [38], the behavior of clathrate hydrates during crystals growth is studied using an optical cell under pressure. The study described in the work [39] was one of the first to develop a method for quantitative measurement of film thickness using microscopy. In 2001, Freer et al. used optical microscopy as a tool to determine the rate of growing the methane hydrate film depending on the bulk temperature [40]. In addition, the authors of works [41-49] and many others used in their research the method of visual monitoring for the processes in the systems with gas hydrates.

In this work, in the process of developing the research methods, attention was focused on capturing and analyzing photo and video images of the gas hydrates formation in multicomponent gas mixtures (natural gas) in contact with aqueous solutions of ionic and nonionic substances (e.g. reservoir water, sea water, reservoir and sea water in a mixture with hydrate formation inhibitors). The studies are performed on laboratory equipment shown in Fig. 5.

The optimal level of image magnification, which would be the most informative and technically acceptable for implementation in laboratory equipment, has been analyzed in the process of research. In this case, the presence of a transparent layer of glass in the viewing window of the reactor (16 mm thick) between the tested sample in the reactor and the microscope lens is a technical problem. That is, the restriction relates to the minimum focal length, and hence the magnification factor of the resulting image. On the other hand, during the laboratory testing of the method, it has been determined that a significant image magnification (more than by 150-200 times) complicates the search for an informative 
object of study (behind the glass of viewing window of the reactor of relatively large area, especially in the case of mixing its content or bubbling) and assessment of the overall picture of the process.

(a)

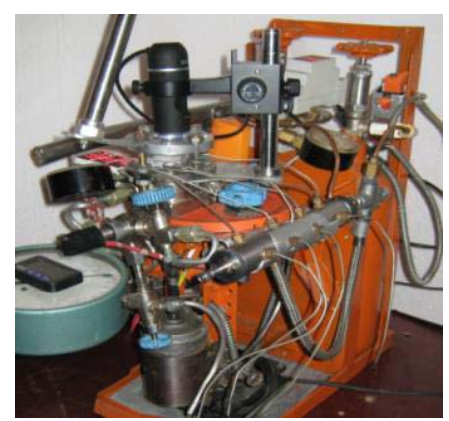

(b)

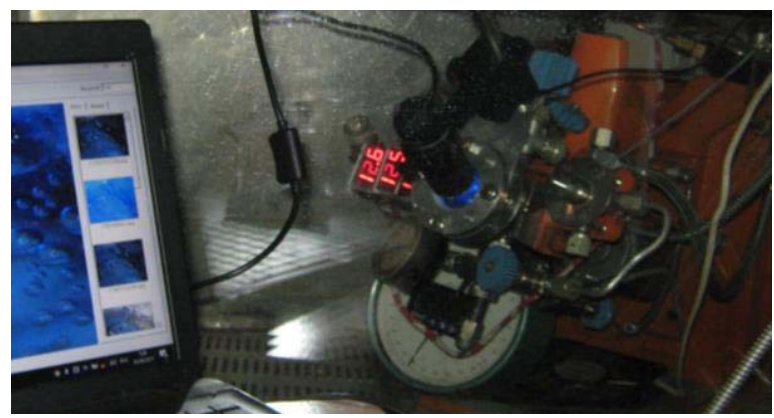

Fig. 5. Laboratory equipment: (a) appearance; (b) research process.

In addition, the main studied objects, such as water, aqueous solutions, inhibitors, gas hydrate and ice, are mostly colorless and transparent. The lack of objects coloring and its certain elements significantly complicates the obtaining of informative images of hydrate formation processes. The idea of adding color dyes to the reactor is unacceptable, because they can affect the process and thus distort the information. In this regard, the "painting" of the reactor content by illuminating it with light sources of different colors is used. Moreover, to achieve the most positive result in the "manifestation" of the interphase boundaries, the possibility of selecting the optimal color spectrum, direction and intensity of lighting (Figs. 6 and 7) is provided.

(a)

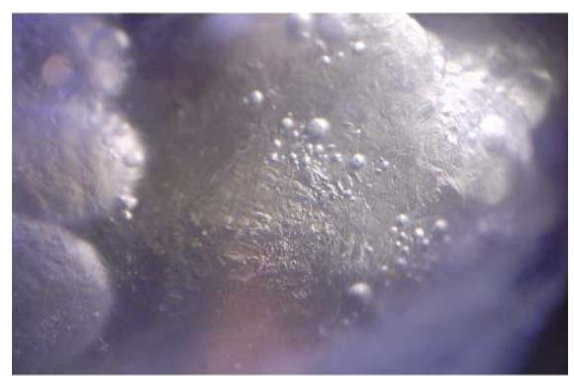

(c)

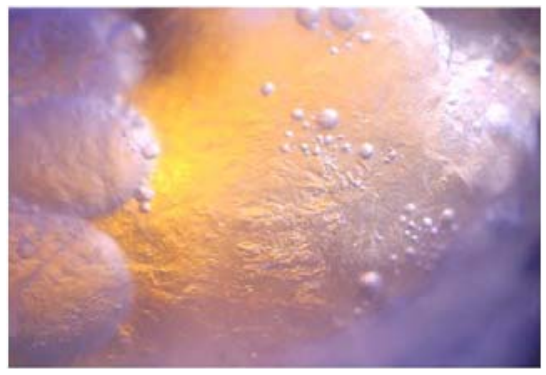

(b)

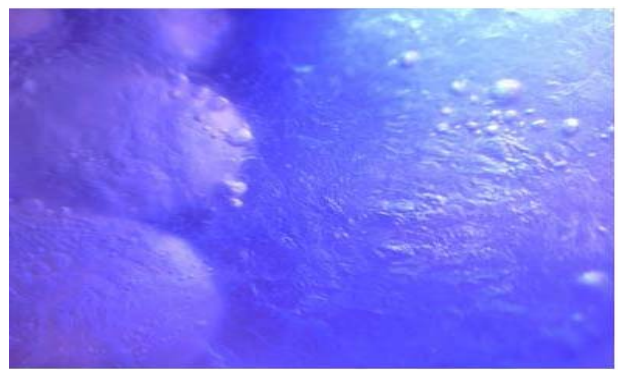

(d)

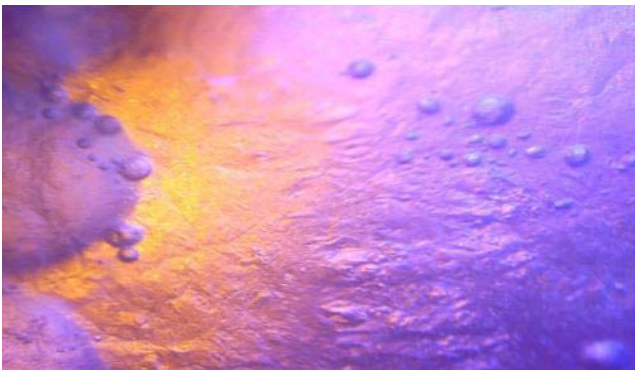

Fig. 6. Options for selecting the light (color) spectrum of hydrate film on the water surface (magnification by 100 times). 
(a)

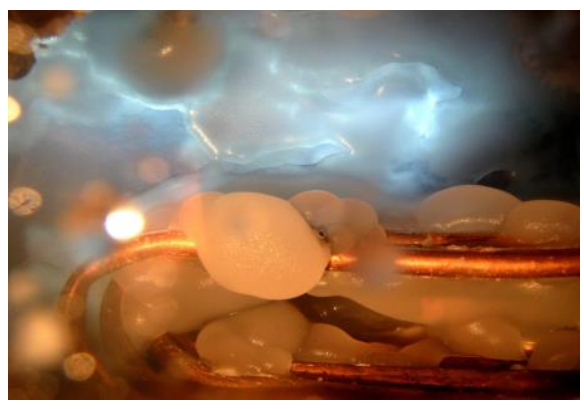

(b)

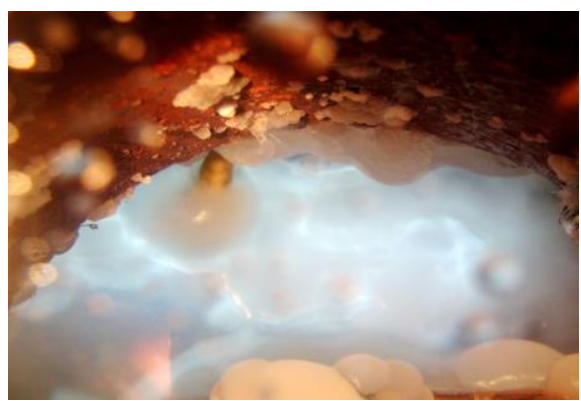

Fig. 7. Option of "painting" the processes in the reactor (without magnification).

Thus, the proposed method consists in determining the parameters of the hydrate formation beginning on the basis of fixing the optical effect of the light source reflection distortion on the mirror-like "liquid-gas" interphase surface.

\section{Conclusions}

The hydrate formation process at the interphase boundary is manifested by the formation of hydrate thin layer in the form of a film. Visually, this process is fixed by the transformation of the mirror-like surface of the phases boundary to matte one. This effect of the interphase boundary distortion is explained by the formation, growth, chaotic accumulation and localization at this boundary of hydrate microcrystals of different shapes and sizes. Simultaneously with the process of interphase surface turbidity, there is a significant distortion of the light source reflection spots. This optical effect makes it possible to extremely sensitively (with high accuracy) record the changes occurring at the microlevel with a mirror-like interphase "gas-liquid" surface. Thus, the proposed method is in determining the parameters of beginning the hydrate formation based on the fixation of the optical effect of the light source reflection distortion on the mirror-like "liquid-gas" interphase surface.

The group of authors expresses their gratitude to the organizing committee of the conference "Gas Hydrate Technologies: Global Trends, Challenges and Horizons" and to the Department of Mining Engineering and Education in particular for the collaboration in research and for the development of the direction of gas hydrate technologies in Ukraine.

\section{References}

1. Kvenvolden, K. (1993). Gas hydrates - geological perspectives and global change. Reviews of Geophysics, 31(2), 173-187. https://doi.org/10.1029/93rg00268

2. Bondarenko, V., Kovalevs'ka, I., \& Ganushevych, K. (2014). Progressive technologies of coal, coalbed methane, and ores mining. London, United Kingdom: CRC Press, Taylor \& Francis Group. https://doi.org/10.1201/b17547

3. Pivnyak, G., Bondarenko, V., \& Kovalevska, I. (2015). New developments in mining engineering 2015. London, United Kingdom: CRC Press, Taylor \& Francis Group. https://doi.org/10.1201/b19901

4. Dreus, A.Уu., Bondarenko, V.I., Biletskyi, V.S., \& Lysenko, R.S. (2020). Mathematical simulation of heat and mass exchange processes during dissociation of gas hydrates in a porous 
medium. Naukovyi Visnyk Natsionalnoho Hirnychoho Universytetu, 5(179), 33-39. https://doi.org/10.33271/nvngu/2020-5/033

5. Bondarenko V., Kovalevska I., Astafiev D., Malova O. (2018). Examination of phase transition of mine methane to gas hydrates and their sudden failure - Percy Bridgman's effect. Solid State Phenomena, (277), 137-146. https://doi.org/10.4028/www.scientific.net/SSP.277.137

6. Bondarenko, V., Svietkina, O., \& Sai, K. (2018). Effect of mechanoactivated chemical additives on the process of gas hydrate formation. Eastern-European Journal of Enterprise Technologies, 6(91), 17-26. https://doi.org/10.15587/1729-4061.2018.123885

7. Kvenvolden, K.A., \& Rogers, B.W. (2005). Gaia's breathglobal methane exhalations. Marine and Petroleum Geology, 22(4), 579-590. https://doi.org/10.1016/j.marpetgeo.2004.08.004

8. Bondarenko, V., Svietkina, O., Lysenko, R., \& Liu, B. (2020). Methane gas hydrates influence on sudden coal and gas outbursts during underground mining of coal deposits. E3S Web of Conferences, (201), 01002. https://doi.org/10.1051/e3sconf/202020101002

9. Sloan, E.D. (2003). Fundamental principles and applications of natural gas hydrates. Nature, 426(6964), 353-363. https://doi.org/10.1038/nature02135

10. Sloan, E.D., Koh, C., \& Sum, A.K. (2009). Natural gas hydrates in flow assurance. Golden, United States: Colorado School of Mines.

11. Kinnari, K., Hundseid, J., Li, X., \& Askvik, K.M. (2015). Hydrate management in practice. Journal of Chemical \& Engineering Data, 60(2), 437-446. https://doi.org/10.1021/je500783u

12. Sloan, E., Koh, C., \& Sum, A. (2010). Natural gas hydrates in flow assurance. London, United Kingdom: Elsevier, Gulf Professional Publishing.

13. Zain, Z.M., Yang, J., Tohidi, B., Cripps, A., \& Hunt, A. (2005). Hydrate monitoring and warning system: A new approach for reducing gas hydrate risks. SPE Europec/EAGE Annual Conference. https://doi.org/10.2118/94340-MS

14. Mazloum, S., Chapoy, A., Yang, J., \& Tohidi, B. (2011). Developing a robust hydrate early warning system. Proceedings of the 7th International Conference on Gas Hydrates (ICGH 2011), 2155-2166.

15. Kawasaki, T., Kikuchi, K., Terasaki, D., Okui, T., Miyata, K., Hirayama, H., \& Masaru, I. (2002). Composition of guests in hydrates from gas mixture. Proceedings of the Fourth International Conference on Gas Hydrates, (2), 488.

16. Tohidi, B., Anderson, R., Chapoy, A., Yang J., \& Burgass, R.W. (2012). Do we have new solutions to the old problem of gas hydrates? Energy \& Fuels, 26(7), 4053-4058. https://doi.org/10.1021/ef3002179

17. Yang, J., Chapoy, A., Mazloum, S., \& Tohidi, B. (2012). Minimizing hydrate inhibitor injection rates. International Petroleum Technology Conference, (27), 376-381. https://doi.org/10.2523/IPTC-17835-MS

18. Tohidi, B., Chapoy, A., Yang, J., Ahmadloo, F., Valko, I., \& Zain, Z.M. (2008), OTC 19247 developing hydrate monitoring and early warning systems. OTC 08 "Waves of Change", (1), 515-523.

19. Sloan, E.D., \& Koh, C.A. (2008). Clathrate hydrates of natural gases. London, United Kingdom: CRC Press. https://doi.org/10.1201/9781420008494

20. Turner, D.J. (2005). Clathrate hydrate formation in water-in-oil dispersions. PhD Thesis. Golden, United States: Colorado School of Mines.

21. Lee, J.D., Susilo, R., \& Englezos, P. (2005) Methane-ethane and methane-propane hydrate formation and decomposition on water droplets. Chemical Engineering Science, (60), 4203-4212. https://doi.org/10.1016/j.ces.2005.03.003

22. Ohmura, R., Ogawa, M., Yasuoka, K., \& Mori, Y.H. (2003). Statistical study of clathrate-hydrate nucleation in a water/hydrochlorofluorocarbon system: Search for the nature of the "memory effect". The Journal of Physical Chemistry, 107(22), 5289-5293. https://doi.org/10.1021/jp027094e 
23. Parent, J.S., \& Bishnoi, P.R. (1996). Investigations into the nucleation behaviour of natural gas hydrates. Chemical Engineering Communications, (144), 51-64. https://doi.org/10.1080/00986449608936444

24. Sloan, E.D., \& Koh, C.A. (2008). Clathrate hydrates of natural gases. New York, United States: Taylor and Francis. https://doi.org/10.1201/9781420008494

25. Buchanana, P., Soper, A.K., Thompson, H., Westacott, R.E., Creek, J.L., Hobson, G., \& Koh, C.A. (2005). Search for memory effects in methane hydrate: Structure of water before hydrate formation and after hydrate decomposition". Journal of Chemical Physics, 123(16), 4507. https://doi.org/10.1063/1.2074927

26. Sloan, E.D., Subramanian, S., Matthews, P.N., Lederhos, J.P., \& Khokhar, A.A. (1998). Quantifying hydrate formation and kinetic inhibition. Industrial \& Engineering Chemistry Research, 37(8), 3124-3132. https://doi.org/10.1021/ie970902h

27. Bishnoi, P.R., \& Natarajan, V. (1996). Formation and decomposition of gas hydrates. Fluid Phase Equilibria, 117(1-2), 68-177. https://doi.org/10.1016/0378-3812(95)02950-8

28. Englezos, P., Kalogerakis, N., Dholabhai, P.D., \& Bishnoi, P.R. (1987). Kinetics of formation of methane and ethane gas hydrates. Chemical Engineering Science, 42(11), 2647-2658. https://doi.org/10.1016/0009-2509(87)87015-X

29. Sloan, E.D. (1998). Gas hydrates: Review of physical/chemical properties. Energy \& Fuels, 12(2), 191-196. https://doi.org/10.1021/ef970164

30. Mazloum, S., Chapoy, A., Yang, J., \& Tohidi, B. (2011). Online monitoring of hydrate safety margin. Proceedings of the 7th International Conference on Gas Hydrates (ICGH 2011).

31. Babakhani, S.M., Bouillot, B., Ho-Van, S., Douzet, J., \& Herri, J.-M. (2018). A review on hydrate composition and capability of thermodynamic modeling to predict hydrate pressure and composition. Fluid Phase Equilibria, (472), 22-38. https://oi.org/10.1016/j.fluid.2018.05.007

32. Song, G., Li, Y., Wang, W., Jiang, K., Ye, X., \& Zhao, P. (2017). Investigation of hydrate plugging in natural gas + diesel oil + water systems using a high-pressure flow loop. Chemical Engineering Science, (158), 480-489. https://doi.org/10.1016/j.ces.2016.10.045

33. Ruan, C., Ding, L., Shi, B., Huang, Q., \& Gong, J. (2017). RSC Advances, (7), 48127-48135. https://doi.org/10.1039/C7RA09269E

34. Nicholas, J.W., Koh, C.A., Sloan, E.D., Nuebling, L., He, H., \& Horn, B. (2009). Measuring hydrate/ice deposition in a flow loop from dissolved water in live liquid condensate. AIChE Journal, 55(7), 1882-1888. https://doi.org/10.1002/aic.11874

35. Joshi, S.V., Grasso, G.A., Lafond, P.G., Rao, I., Webb, E., Zerpa, L.E., Sloan, E.D., Koh, C.A., \& Sum, A.K. (2013). Experimental flowloop investigations of gas hydrate formation in high water

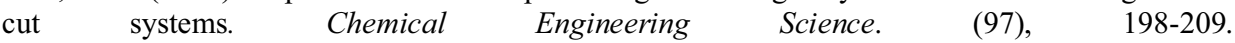
https://doi.org/10.1016/j.ces.2013.04.019

36. Chen, K.-L., Yan, G.-J., Chen, C.-Y., Sun, B., Liu, N., Ren, D.-J., Shen, M., Niu, Y.-N., Li, N., \& Sum, A.K. (2015). Insights into the formation mechanism of hydrate plugging in pipelines. Chemical Engineering Science, (122), 284-290. https://doi.org/10.1016/j.ces.2014.09.039

37. Lv, X.F., Shi, B.H., Wang, Y., Tang, Y.X., Wang, L., \& Gong, J.Y. (2015). Experimental study on hydrate induction time of gas-saturated water-in-oil emulsion using a high-pressure flow loop. Oil \& Gas Science and Technology - Revue d'IFP Energies Nouvelles, 70(6), 1111-1124. https://doi.org/10.2516/ogst/2014032

38. Eugene, A., Smelik, H.E., \& King, Jr. (1997). Crystal-growth studies of natural gas clathrate hydrates using a pressurized optical cell. American Mineralogist, (82), 88-98. https://doi.org/10.2138/am-1997-1-211

39. Kobayashi, I., Ito, Y., \& Mori, Y.H. (2001). Microscopic observations of clathrate hydrate films formed at liquid/liquid interfaces. I. Morphology of hydrate films. Chemical Engineering Science, 56(14), 4331-4338. https://doi.org/10.1016/S0009-2509(00)00544-3

40. Freer, E.M., Selim, S.M., \& Sloan, E.D. (2001). Methane hydrate film growth kinetics. Fluid Phase Equilibria, 185(1-2), 65-75. https://doi.org/10.1016/S0378-3812(01)00457-5 
41. Choukroun, M., Grasset, O., Tobie, G., \& Sotin, C. (2010). Stability of methane clathrate hydrates under pressure: Influence on out gassing processes of methane on Titan. Icarus, 205(2), 581-593 https://doi.org/10.1016/j.icarus.2009.08.011

42. Imasato, K., Aifaa, M., \& Ohmur, R. (2013) Crystal growth of clathrate hydrate in flowing liquid water system saturated with methane gas. Crystal Growth \& Design, 15(2), 559-563. https://doi.org/10.1299/jsmemecj.2013. G061046-1

43. Seo, Y., \& Kang, S-P. (2011). Dependence of drawdown pressure on the hydrate reformation during methane hydrate production and its inhibition with kinetic hydrate inhibitors. Proceedings of the 7th International Conference on Gas Hydrates (ICGH 2011), 137-138.

44. Bin, D., Zhang, L., Wu, X., Ning, F., Tu, Y., \& Jiang, G. (2008). Effect of SDS and THF on formation of methane-containing hydrates in pure water. Proceedings of the 6th International Conference on Gas Hydrates (ICGH 2008).

45. Pedchenko, L.O., \& Pedchenko, M.M. (2014). The forcibly preservation of gas hydrate blocks by layer of ice. Mining of Mineral Deposits, 8(3), 277-286. https://doi.org/10.15407/mining08.03.277

46. Melnikov, V.P., Nesterov, A.N., Reshetnikov, A.M., \& Zavodovsk, A.G. (2009). Evidence of liquid water formation during methane hydrates dissociation below the ice point. Chemical Engineering Science, (64), 1160-1166. https://doi.org/10.1016/j.ces.2008.10.067

47. Chou, I-M., Sharma, A., Burruss, R.C., Shu, J., Mao, H., Hemley, R.J., Goncharov, A.F., Stern, L.A., \& Kirby, S.H. (2000). Transformations in methane hydrates. Proceedings of the National Academy of Sciences, 97(25), 13484-13487. https://doi.org/10.1073/pnas.250466497

48. Cheng, C-X., Tian, Y-J., Wang, F.W., Zheng, J-L., Zhang, J., Li, L-W., \& Yang, P. (2019). Experimental study on the morphology and memory effect of methane hydrate reformation. Energy \& Fuels, 33(4), 3439-3447. https://doi.org/10.1021/acs.energyfuels.8b02934

49. Rao, I., Koh, C.A., Sloan, E.D., \& Sum, A.K. (2013). Gas hydrate deposition on a cold surface in water-saturated gas systems. Industrial \& Engineering Chemistry Research, 52(18), 6262-6269. https://doi.org/10.1021/ie400493a 